\title{
EVALUATION OF THE EFFECT OF MONOSODIUM GLUTAMATE ADMINISTRATION ON BUCCAL MUCOSA OF ADULT MALE ALBINO RATS. (HISTOLOGICAL AND IMMUNO-HISTOCHEMICAL STUDY)
}

\author{
Heba Fathy El Imam * and Nesreen Nabil abd El Salam **
}

\begin{abstract}
Introduction: The material we have in our hands represents a commonly used additive for enhancing the savor of different foods producing an exceptional kick. The oxidative stress might be augmented by high intake of MSG and results in cytotoxicity of various tissues.

Aim: To evaluate the effects of MSG on the buccal mucous membrane of rats (male, adult, albino) through histological and immune-histochemical investigations.

Material and methods: Thirty adult male albino rats $(n=30)$ were used in this study. Random division of the samples were done, grouping those samples within 2 alike groups; group I and group II ( $\mathrm{n}=15$ rats). Group I (Control); rats were treated by distilled water $(2 \mathrm{ml})$ daily by gastric tube, and Group II (MSG treated); rats were given MSG daily using a $30 \mathrm{mg} / \mathrm{kg}$ dosage which is thawed in ( $2 \mathrm{ml}$ ) distilled water by gastric tube. Rats of all groups, were euthanized and sacrificed six weeks after the start of experiment. Specimens from buccal mucosa were dissected out and processed where, Hematoxylin and Eosin and Mallory trichrome stains were used at one part, and in the other part immuno-histochemical stains were utilized for identifying the expression of (PCNA) gene.
\end{abstract}

Results: The histological results of the buccal mucous membrane of MSG- supplemented group as compared, to control group, exposed shrivelled epithelial alterations, alongside degenerated cells having pyknotic nuclei. While, the collagen fibers were strongly deposited at lamina propria with dilated and congested blood vessels and immunohistochemical results revealed many epithelial cells with a strong brown positive PCNA.

Conclusion: Low doses of monosodium glutamate-induced degenerative effects on the buccal mucosa of rats. Subsequently, we recommend, to restrict, the using of MSG as food flavor enhancer.

KEY WORDS: Monosodium glutamate, buccal mucosa.

* Lecturer of Oral Biology, Faculty of Dentistry, Egyptian Russian University, Cairo, Egypt.
** Lecturer of Oral Biology, Faculty of Dentistry, Mansoura University, Mansoura, Egypt. 


\section{INTRODUCTION}

Food additives are substances that applied to the food to produce a special color or taste. Monosodium glutamate (MSG) is the sodium salt of glutamic acid (GA) which contains $78 \%$ of glutamic acid, $22 \%$ of sodium and water. It has different names in many countries such as Ajinomoto, Chinese salt, and E621 and commonly used in many food products such as chips, noodles, and soups ${ }^{(1)}$. In an aqueous solution, MSG dissociates into free glutamate that binds to taste receptors on taste cells in the oral cavity and activates taste nerves to elicit the umami taste ${ }^{(2)}$.

Glutamate is produced in the body and has a role in body metabolism. It is a major component of many protein-rich food products either in free or bounded state. GA does exist within most foodstuffs, including green vegetables origins such as mushroom and tomato, meat and seafood ${ }^{(3,4)}$. United State Food and Drug Administration (FDA) categorized MSG as generally safe with no particular daily intake limit and described by the European Union as a food additive (E621), a "Flavoring agent" or "Hydrolyzed vegetable protein" (5).

MSG influences the appetite positively, and induces weight gain through its stimulation of the orosensory receptors and by improving the palatability of meals. Many previous reports, indicate that MSG is toxic to both human and experimental animals in spite of its taste stimulation and enhanced appetite ${ }^{(6)}$.

Intake of high amounts of MSG as food flavoring agent can increase the oxidative stress and results in cytotoxicity ${ }^{(7)}$ and damage effect on various organs of the body, such as neurotoxic effects on the cerebellum and pre-neoplastic changes in the liver ${ }^{(\mathbf{8})}$.

The MSG toxicity was further emphasized by experiment on the testis in a dose-dependent fashion rats, causing oligo-zoospermia and increase abnor- mal sperm morphology. Reports say that MSG may be involved male infertility cases because it results in testicular hemorrhage, sperm cell population alteration and morphology degeneration ${ }^{(9)}$.

Moreover, it was established that MSG cause damage of pancreatic structure at both exocrine and endocrine cells ${ }^{(10)}$. Also, high doses than normal dietary intake resulted in oxidation or metabolization of its molecules by the mucosa into other nonessential amino acids ${ }^{(4)}$.

The human buccal oral mucous membrane consists of two layers: an outer layer of stratified squamous epithelium; composed of the four layers: stratum basale resting on the basement membrane followed by stratum spinosum, stratum granulosum, and an underlying layer of dense connective tissue (lamina propria) that having underneath a submucosa containing blood vessels, nerves, fat and glands. The oral mucosa has structural modifications at different regions of the oral cavity meanwhile it considered as a mirror that reflects the general health of the individual ${ }^{(11)}$.

Proliferating cell nuclear antigen (PCNA) which is a vital cell cycle regulator, has a role as, a co-factor for DNA polymerase delta in S-phase. It is the auxiliary protein of DNA polymerise- 5 and concentrated in the nucleus and it plays an important role in DNA synthesis, DNA repair and cell proliferation (12). PCNA levels are very low and undetectable in quiescent cells, and produced before DNA replication. This protein increases at G1 and S phase and decreases at G2 phase of the cell cycle. So, it is a more sensitive index of cell proliferation ${ }^{(13)}$.

Few studies have been done to examine the adverse effect of MSG intake on the oral mucosa. So, this study has been done to evaluate the effects of MSG on the buccal mucous membrane of adult male albino rats by histological and immunehistochemical analyses. 


\section{MATERIALS AND METHODS}

\section{Animals:}

Thirty adult male albino rats, weighing between 150 -200 gm were obtained from animal house. Rats housed in Medical Experimental Research Center (MERC) in Faculty of Medicine, Mansoura University. All experimental procedures were performed under protocol of ethical committee of Faculty of Dentistry, Mansoura University, Egypt. They properly ventilated at constant temperature $\left(24^{\circ} \mathrm{C}\right)$, in separate stainless steel cages and fed a standard pelleted.

\section{Chemicals:}

- Monosodium Glutamate (MSG). It was sold in most super markets in Egypt under the license of Ajinomoto Co. Inc. (Tokyo, Japan). This product available in the form of crystals easily dissolve in water.

\section{Study design:}

Animals were allocated among two groups (15 rats for each one):

- Group I (Control group): rats were received $2 \mathrm{ml}$ distilled water daily by gastric tube for 6 weeks.

- Group II (MSG treated group): rats were received $30 \mathrm{mg} / \mathrm{kg}$ body weight of MSG dissolved in $2 \mathrm{ml}$ distilled water daily by gastric tube for 6 weeks ${ }^{(14) .}$

At the end of the experimental period, the animals of both groups were sacrificed by ketamine over dose (15). Then, longitudinal specimen was dissected out from buccal mucosa from each rat of size about $5 \mu \mathrm{m}$ thick. Each specimen was obtained and immediately fixed in $10 \%$ formalin solution. Tissue sections were processed for paraffin blocks in histology department, Faculty of Medicine, Al Azhar University.

\section{Histological techniques:}

One set of sections of $5 \mu \mathrm{m}$ thick were obtained from the paraffin blocks using a rotatory microtome and stained with H\&E and Mallory trichrome stain (16). In another set of sections, immune-histochemical staining was performed to detect the proliferating cell nuclear antigen (PCNA).

Computer Assisted digital image analysis (Digital morphometric study):

Slides were photographed using Olympus ${ }^{\circledR}$ digital camera installed on Olympus ${ }^{\circledR}$ microscope with $1 / 2 \mathrm{X}$ photo adaptor, using $40 \mathrm{X}$ objective. The images were analyzed on Intel ${ }^{\circledR}$ Core $\mathrm{I} 3 \AA$ based computer using Video Test Morphology ${ }^{\circledR}$ software (Russia) with a specific built-in routine for distance measurement and stain quantification. Slides from each rat were prepared, 5 random fields from each slide were analyzed.

\section{Statistical analysis:}

Data was analyzed using Statistical Package for Social Science software computer program version 23 (SPSS, Inc., Chicago, IL, USA). Data were presented as mean and standard deviation. One way Analysis of variance (ANOVA) and post-hoc Tukey tests were used for comparing different groups in the study. P value less than 0.05 is statistically significant.

\section{RESULTS:}

\section{Histological results:}

\section{Haematoxylin and Eosin (H\&E) Stain}

\section{Group I (control group):}

Histological results of buccal mucosa of this group showed normal histological features of the buccal mucosa, normal epithelial thickness with normal sized epithelial cells that tightly packed with no intercellular bridge disruption and normal 


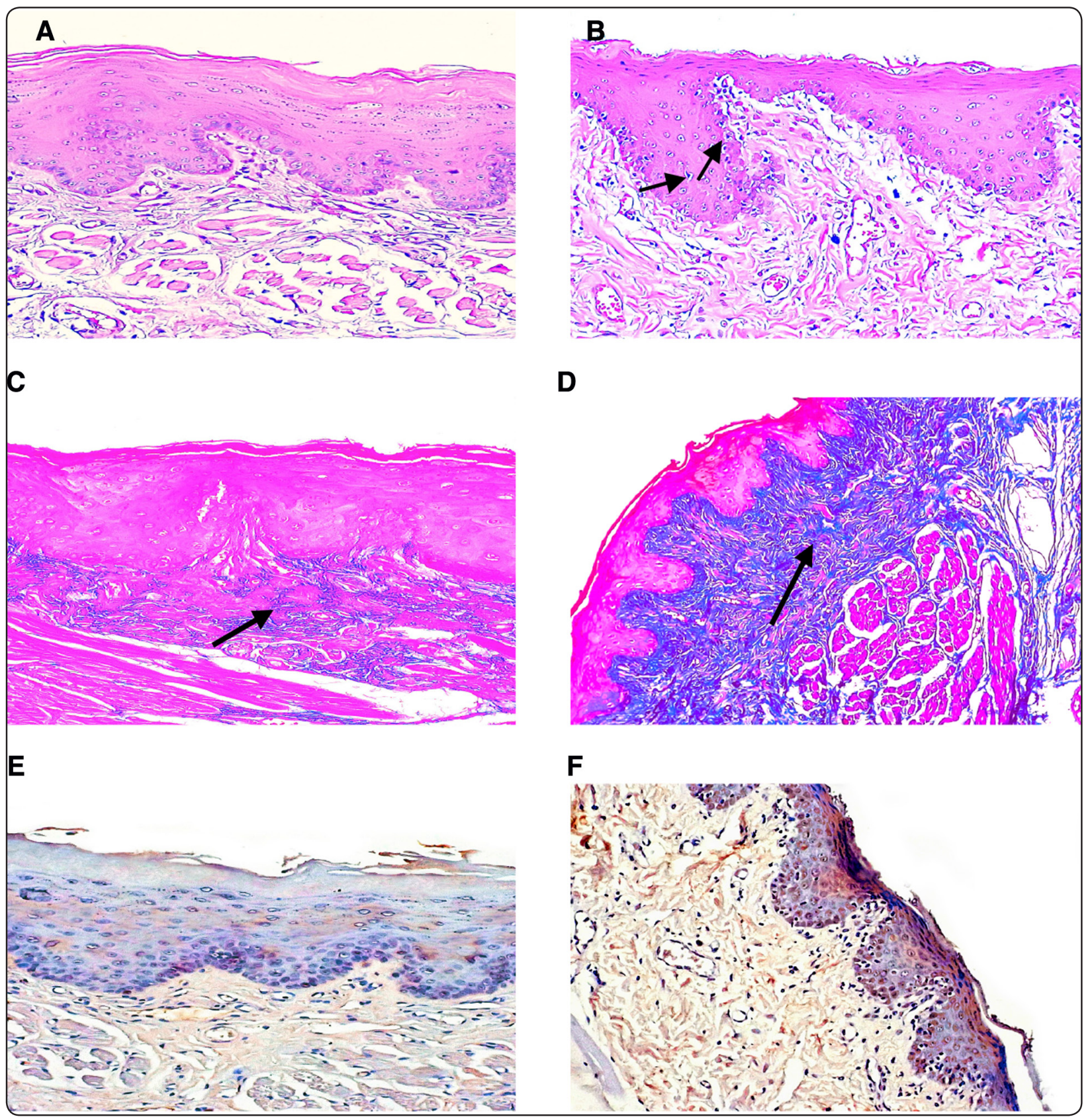

Fig. (1) A photomicrograph of buccal mucosa from two groups showing: (a) Normal epithelial thickness, normal sized epithelial cells that tightly packed with no intercellular bridge disruption, well defined epithelial rete pegs and normal nuclei appearance (H\&E X 400). (b) Marked epithelial atrophy, epithelial cells with intercellular bridge disruption, degenerated cells with pyknotic nuclei and apoptotic cells appearance (arrow) (H\&E X 400). (c) Thin collagen fiber were observed in the thin lamina propria (arrow) (Mallory trichrome X 400). (d) Strong deposition of collagen fibers in the lamina propria and the blood capillaries were dilated and markedly congested (arrow) (Mallory trichrome X 400). (e) Weak brown positive PCNA reaction at only few basal cells (PCNA X 400). (f) Strong brown positive PCNA reaction in many basal cells (PCNA $\mathrm{X} 400)$.

(a, c, e figures representing group I \& b, d, f figures representing group II). 
nuclei appearance (fig 1a). The epithelium showed well defined rete pegs projecting into the normal underlying lamina propria and no inflammatory cells infiltration. Thin collagen fiber bundles were observed in the lamina propria (fig 1c).

\section{Group II (MSG treated group):}

Histological results of buccal mucosa of this group showed marked epithelial atrophy, epithelial cells with intercellular bridge disruption, degenerated cells with pyknotic nuclei, flattening or shortening of rete ridge, and destruction of some basal cells was also seen (fig 1b). Strong deposition of collagen fibers were be seen in the lamina propria. Increase the number of dilated blood vessels that markedly congested with extravagated red blood cells (fig 1d).

\section{Immunohistochemical stain results:}

The basal cells at (group I), showed weakly brown positive PCNA reaction in few number of cells (fig 1e). While at (group II), the basal cells showed strong brown positive PCNA reaction in many cells (fig 1f).

\section{Statistical results}

\begin{tabular}{|c|c|c|c|}
\hline & Group I & Group II & P \\
\hline Trichrome(\%Area) & $16.61 \pm 2.32$ & $27.39 \pm 0.81$ & $<0.001 *$ \\
\hline Immuno(\%Area) & $0.75 \pm 0.14$ & $1.67 \pm 0.82$ & $<0.02 *$ \\
\hline
\end{tabular}

Data expressed either as mean $\pm S D$

\section{SD:standard deviation}

P:Probability *:significance $<0.05$

Test used: One way ANOVA followed by post-hoc Tukey

P1: significance relative to Group I

P2: significance relative to Group II

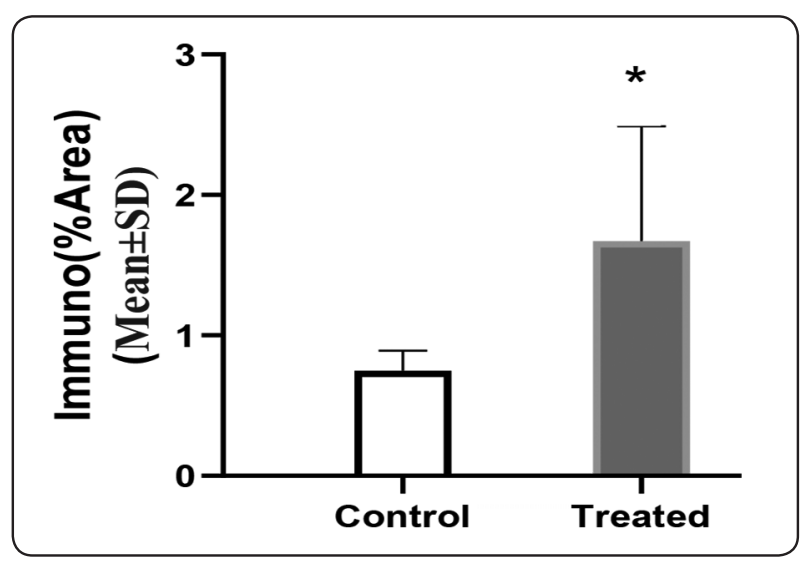

Fig 2: bar chart of PCNA area for 2 groups

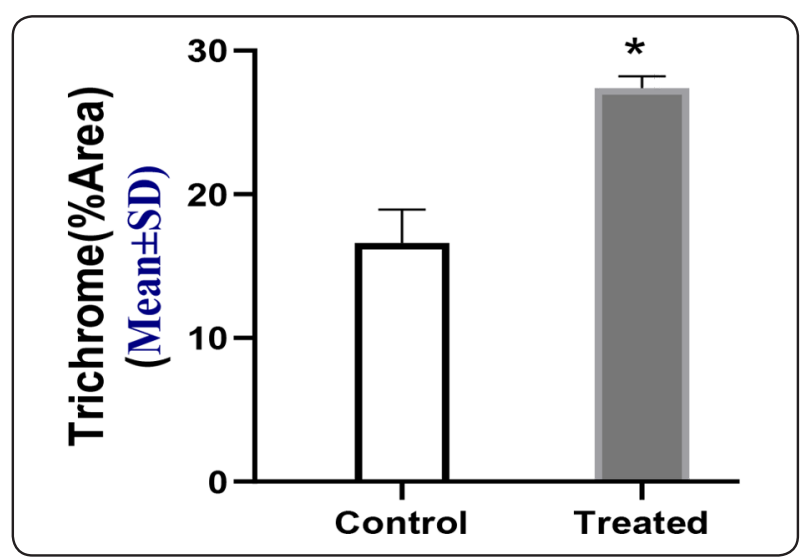

Fig 3: bar chart of Trichrome area for 2 groups

\section{DISCUSSION}

Monosodium glutamate is commonly used to provide food flavoring effect comparable to the naturally free glutamate and applied to canned foods, processed meat and soups to increase the palatability and taste. Although, it has side toxic effects for human and animals including allergic reaction; flushing, sweating, numbness, weakness, dizziness and headaches as explained by Tawfik and AlBadr, $2012{ }^{(5)}$. These findings were confirmed by Pavlovic and Sarac, $2010{ }^{(17)}$ who stated that unbound glutamate dissociated from MSG could act on certain receptors in the central or peripheral neurons, causing degenerative changes.

This is study was designed to evaluate the histological and immune-histochemical effect of 
MSG as food additive on the buccal mucosa of adult male albino rats.

It should be mentioned that normally the epithelium of the buccal mucosa of albino rats is keratinized stratified squamous epithelium of the four layers: stratum basale resting on the basement membrane followed by stratum spinosum, stratum granulosum and stratum corneum ${ }^{(18)}$.

The histological examination (Heamatoxylin and Eosin stain) revealed that: at group I, normal histological features of the buccal mucosa (keratinized stratified squamous epithelium). Their epithelial layers were intact with regular epithelial thickness and intercellular connections with intact nuclei. While, epithelial thickness at group II was atrophied than control group. This findings were occurred as a result of proliferation in cell death and decrease in cell number and there were signs of apoptosis. Also, our results showed reflected nuclear pyknosis and intercellular bridge disruption. These findings were in agreement with Oluwole and Iyortim, (2006) ${ }^{\left({ }^{(9)}\right)}$ who revealed that MSG intake caused non-uniform histopathological degenerative changes in the gastric mucosa of rats that might lead to onset of gastric ulcer.

Moreover, Eweka and Om Iniabohs, (2007) (1) reported that rats which received $3 \mathrm{~g}$ of MSG, their gastric mucosa revealed increased the basophilia with cellular hypertrophy. While, the intake of $6 \mathrm{~g}$ of MSG lead to more evident degenerative and atrophic changes. Conversely to our results, Numan et al., (2010) ${ }^{(20)}$ explained that MSG induced increasing in the thickness of gastric mucosa with statisticalsignificant values, also Ilegbedion et al., (2013) ${ }^{(21)}$ reported that no deleterious effects of MSG with no prominent deformity of gastric mucosa after its administration.

At the current study, many histological changes were appeared at the buccal mucosa as a result of MSG administration. Represented by shortening of epithelial rete ridge and destruction of some basal cells while the superficial mucosa showed dilated blood vessels that were markedly congested. These findings were in agreement with those of Oluwole and Iyortim (2006) ${ }^{(\mathbf{1 9 )})}$ who revealed that MSG treated rats, showed increasing in destructed cells, and edematous lamina propria that comprising many inflammatory cells with congested blood vessels. Also, Falalieieva et al., (2010) ${ }^{(22)}$ stated that when rats received doses of 15 to $30 \mathrm{mg} / \mathrm{kg}$ MSG for 10-, 20-, 30-days demonstrated erosive and ulcerative changes in gastric mucosa and increasing in the secretion of hydrochloric acid.

The cell death and atrophy of surface epithelial cell detected in Group II of this study could be attributed to MSG has a strong direct damage of cellular membrane leading to defect in cell permeability. This finding was agreed with the observation of Raju et al., (2009) ${ }^{(23)}$ who reported that the rapid penetration of ethanol into the gastric mucous membrane caused cell and plasma membrane damage and high intracellular membrane permeability to sodium and water leading to cell death and exfoliated surface epithelial layers.

Regarding the histochemical results (Mallory trichrome stain), at group I (control group), thin collagen fiber were detected in the lamina propria while in group II (MSG treated group), severe dilated and congested blood capillaries, many inflammatory cells infiltrated and marked collagen fibers formation. These results is analogous in many respects to that of Mohamed (2010) ${ }^{\text {(24) }}$ after a single dose of Non-Steroidal Anti-inflammatory Drug at rats gastric mucous membrane.

In our present study, at group II, marked deposition of collagen fibers in the lamina propria mainly around blood vessels lead to decrease in the blood flow to buccal mucosa then ischemia and degeneration. So, the area of the lamina propria revealed a highly statistical significant with intense reaction of trichrome staining of collagen fibers deposited. These findings were in many respect 
to Damiano et al., (1990) ${ }^{(25)}$ who reported that damaged epithelial cells has fibroblast activation, cell division and collagen fibers deposited.

Concerning the immune-histological results of our study revealed that the basal cell at group I showed mild brown positive PCNA expression in few cells. While, at group II, the basal cells showed strong brown positive PCNA expression in many cells. These findings were in consistent with Martinz et al., (1996) (26) who reported PCNA expression in oral lesions with epithelial dysplasia. Shredah and El-Sakhawy (2014) ${ }^{(15)}$ mentioned that the increasing in the expression of PCNA has been observed as tissues processed from normal epithelium to hyperplasia, dysplasia, premalignant and then malignant lesions.

In our result of group II, showed increased in cells stained brown positive PCNA expression with the level of significances at $\mathrm{P}<0.05$. These findings were in accordance with results of Celis and Celis (1985) ${ }^{(27)}$ who attributed the brown positive PCNA expression as the cell preceded in S-phase. Therefore, the strong positive PCNA expression at buccal mucosa, lead to the cell division and increased the proliferative activity needed for regeneration of degenerated epithelial cells of mucosa.

The buccal epithelial cells strong brown positive PCNA expression that appeared in many cells. These results were in accordance with Morsy, et al., (2016) ${ }^{(28)}$ who analyzed the effects of MSG on the gastric mucosa and revealed the gastric mucosa with decreased thickness, widening of gastric glands and gastric pits.

\section{CONCLUSION}

Our results indicate that low doses of monosodium glutamate induced deleterious effects on the buccal mucosa of rats. Subsequently, we recommend to restrict the using of MSG as food flavor enhancer.

\section{REFERENCES}

1. Eweka AO and Om Iniabohs FAE: Histological studies of the effects of monosodium glutamate on the small intestine of adult Wistar rats. Electron Biomed. J. 2007; 2:14-18.

2. Rolls ET: Functional neuroimaging of umami taste: what makes umami pleasant? Am. Clin. Nutr. J. 2009; 90: 804813.

3. Gheller ACGV, Kerkhoff J, Júnior GMV, de Campos KE and Sugui MM: Ant mutagenic effect of Hibiscus sabdariffa L. aqueous extract on rats treated with monosodium glutamate. Sci. World J. 2017:1-8.

4. Burrin DJ and Stoll B: Metabolic fate and function of dietary glutamate in the gut. Am. Clin. Nutr. J. 2009; 90:850-856

5. Tawfik MS and Al-Badr N: Adverse effects of monosodium glutamate on liver and kidney functions in adult rats and potential protective effect of vitamins $\mathrm{C}$ and $\mathrm{E}$. Food Nutr. Sci. J. 2012; 3: 651- 659

6. Rogers PP and Blundell JE: Umani and appetite: Effects of Monosodium glutamate on hunger and food intake in human subjects. Phsiol. Behav. 1990:486:801-804.

7. Nakanishi Y, Tsuneyama K, Fujimoto M, Salunga T and Kazuhiro N: Monosodium glutamate (MSG): a villain and promoter of liver nflammation and dysplasia. Autoimmun. J. 2008; 30:42-50.

8. Falalyeyeva TM, Leschenko IV, Shevchuk VO and Beregova TV: About the influence of long-term injection of monosodium glutamate on pancreas in rats. Euro. Clin. Invest. J. 2012; 42: 45.

9. Onakewhor JUE, Oforofuo IAO and Singh SP: Chronic administration of Monosodium glutamate Induces Oligozoospermia and glycogen accumulation in Wister rat testes. Africa J. Reprod Health 1998; 2:190-197.

10. Iamsaard S, Sukhorum W, Samrid R, Yimdee J, Kanla P, Chaisiwamongkol K, et al.,: The sensitivity of male rat reproductive organs to onosodium glutamate. Acta. Medica. Acad. J. 2014; 43:3-9.

11. Nanci A: Ten cate's. Oral histology. $8^{\text {th }}$ ed. Louis, Baltimore, Boston, Chicago, London, Tokyo Toronto. 2008; 6: 348-349.

12. Tománek M and Chronowska E: Immunohistochemical localization of proliferating Nuclear Antigen (PCNA) in the pig ovary cell. Folia Histochmica et., Cytobiologica J. 2006; 44 (4):269-274 
13. Srinivasan M and Jewell SD. Quantitative estimation of PCNA, c-myc, EGFR and TGF-alfa in oral submucous fibrosis- an immmunohistochemical study. Oral Oncol. J. 2001; 37: 461- 467 .

14. Shredah MT: Molecular study to the effect of monosodium glutamate on rat gingiva. Tanta Dental J. 2017, 14:155-163.

15. Shredah M and El-Sakhawy MA: Immunohistochemical expression of activated caspase- 3 in the parotid salivary glands of rats after long administration of Myristica fragrans. Int. Adv. Res. J. 2014; 2 (12): 493-499.

16. Suvarna SK, Layton C and Bancroft JD: Theory and Practice of histological techniques. 7th ed, Churchill Livingstone, El Sevier, 2013.

17. Pavlovic V and Sarac M: Topical Review: The role of ascorbic acid and monosodium glutamate in thymocyte apoptosis. Bratisl. Lek. Listy. J. 2010; 111 (6): 357 - 360.

18. Sultan AA, Ali AH and Kamal KA: Immunohistochemical study of the effect of green tea extract on methotrexate-induced oral mucositis in albino rats. Cytol. Histol. J. 2014; 5 (3): $1-7$.

19. Oluwole FS and Iyortim MI: Monosodium Glutamate, a possible Threat to Gastric Integrity in Rats. Biol. Sci. J. 2006; 6 (4): $671-674$.

20. Numan AI, Ekanem AU and Garba S. Morphometric Analysis of the Gastrointestinal Mucosa in Monosodium Glutamate-Treated Albino Rats. Kanem Medical Sciences. J. 2010; 4 (1): 8-13.

21. Ilegbedion IG, Onyije FM and Digba KA: Evaluation of MSG on Electrolyte Balance and Histology of Gastroesophageal Mucosa. Middle-East Sci. Res. J. 2013; 18 (2): 163-167.
22. Falalieieva TM, Kukhars'kyı̆ VM and Berehova TV: Effect of long-term monosodium glutamate administration on structure and functional state of the stomach and body weight in rats. Fiziol. Zh. J. 2010; 56(4):102-10 (English Abstract of Ukrainian Article).

23. Raju D, IlangoK, ChitraV and Ashish K: Evaluation of Anti-ulcer activity of methanolic extract of Terminalia chebula fruits in experimental rats. Pharm. Sci. \& Res. J. 2009; 1(3):101-107.

24. Mohamed AAK: Postulated Protective Role of Curcumin on Indomethacin-induced Acute Gastric Mucosal Damage in Adult Albino Rat Histological and Immunohistochemical Study. Egypt. Histol. J. 2010; 33(3): 583 - 593.

25. Damiano VV, Cherian PV, Frankel FR, Steeger JR, Sohn M, Oppenheim D and Weinbaum G: Intraluminal fibrosis induced unilaterally by lobar instillation of $\mathrm{CdCl} 2$ into the rat lung. Am. Pathol.J.1990; 137 (4): 883-894.

26. Martínez-Lara I, González-Moles MA, Ruiz-Avila I, Bravo M, Ramos MC and Fernández-Martínez JA: Proliferating cell nuclear antigen (PCNA) as a marker of dysplasia in oral mucosa. Acta. Stomatol. Belg. J. 1996; 93 (1):29-32.

27. Celis JE and Celis A: Individual nuclei in polykaryons can control cyclin distribution and DNA synthesis. EMBO. J. 1985; 4(5)1192-1187:.

28. Morsy MM, El-Sayed Hassanein GH and Farag AI: Effect of Monosodium Glutamate administration on the Gastric Mucosa of Adult Male Albino Rat: A Histological, Immuno-histochemical and Histomorphometric Study. Nat. Sci. J. 2016; 14(12):134-141. 